\title{
A GESTÃO ESCOLAR COMO AGENTE TRANSFORMADOR DA EDUCAÇÃO
}

\author{
THE SCHOOL MANAGEMENT AS AGENT TRANSFORMER OF EDUCATION
}

\author{
Hermes José Aun Bachiega \\ Mestre Educação: Processos de Ensino, Gestão e Inovação da Universidade de Araraquara \\ UNIARA e Coordenador do Curso de Direito-UNIESP/FAER. E-mail: \\ hermes.bachiega@uniesp.edu.br
}

\section{Edmundo Alves Oliveira}

Doutor em Sociologia pela UNESP. Professor de Sociologia Geral e Jurídica da Universidade de Araraquara - Uniara. Assistente da Coordenação do Curso de Direito da

Universidade de Araraquara UNIARA. Realiza pesquisa na área de sociologia jurídica, política e administração, líder do grupo de pesquisa Direito e Desenvolvimento Público da

Universidade de Araraquara (UNIARA). E-mail: edmundoedmundo@gmail.com

Cibele Barsalini Martins

Professora na Universidade Federal de Santa Catarina - UFSC. Doutora e Mestre em Administração pelo Programa de pós graduação em Administração da Universidade Nove de Julho. Especialista em Qualidade nas Organizações (Lato-sensu), graduada em

Administração pela Universidade Nove de Julho e graduada em Secretariado Executivo pela Universidade São Judas Tadeu. Atualmente está como Coordenadora do Programa de

Pós-graduação em Administração do Centro Socioeconômico da UFSC (Gestão 20172018), Editora Científica da Revista Gestão e Secretariado desde 2010. E-mail: cibele.martins@ufsc.br

Fernando Passos

Mestre em Direito pela Unesp. Chefe do Departamento de Ciências Jurídicas e Coordenador do Curso de Direito e professor da disciplina de Direito Empresarial da Universidade de Araraquara - Uniara. E-mail: fernando@pss.adv.br

Recebido em: 26/09/2017

Aprovado em: 03/12/2017

Doi: $10.5585 /$ rdb.v18i7.786

RESUMO: Este artigo tem por objetivo analisar a importância da gestão escolar a partir da promulgação da Constituição/1988 (CF) e da Lei de Diretrizes de Base/1996 (LDB). Buscou-se, por meio de análise documental com base na metodologia de coleta de documentos como material primordial, com característica interpretativista, realizada a partir de documentos contemporâneos ou retrospectivos considerados autênticos para tratar da gestão escolar. Essa busca passa pelo texto constitucional e pela Lei de Diretrizes de Bases da Educação Nacional (LDB) e é finalizada com uma proposta de utilização de modelo indutivo de administração a partir do Município.

Palavras-Chave: Gestão. Educação, LDB. Constituição Federal/88. 
ABSTRACT: This article aims to analyze the importance of school management on the results of the school from the promulgation of the Federal Constitution/1988 and the Base Guidelines Law/1996. It was sought, by means of documentary analysis based on the methodology for collecting documents as primordial material, with an interpretative characteristic, held from contemporary or retrospective documents considered authentic to handle school management. This search passes through the constitutional text and by the Base Guidelines Law of National Education (LDB) and is finalized with a proposal of utilization of an inductive model of administration from the Municipality.

Keywords: Management. Education. LDB and Federal Constitution/1988.

SUMÁRIO: Introdução; O direito à educação na CF/88: Breve abordagem; Conclusão; Proposição; Referências Bibliográficas.

\section{INTRODUÇÃO}

A competência do gestor no comando da instituição de ensino, e, especificamente neste estudo, trata do gestor escolar, tem sido um assunto discutido em pesquisas na área de educação, visto que a preocupação com a qualidade do ensino está diretamente ligada a determinadas experiências de fracassos no ambiente escolar, algumas delas relacionadas à falta de planejamento e clima organizacional desfavorável, no contexto brasileiro.

Quando das análises às pesquisas levadas a efeito em universidades brasileiras sobre a origem dos bons resultados em instituições que anteriormente possuíam resultado inferior à média do Índice de Desenvolvimento da Educação Básica - Ideb, houve a compreensão de que a competência do gestor ao comandar uma instituição de ensino seja, se não o principal, um dos principais fatores que influenciam nas práticas de sucesso e, por consequência, no processo de aprendizagem dos alunos, pois, muitas vezes, é por meio da ação profissional competente do gestor ao proceder um planejamento cuidadoso, para criar um clima organizacional favorável, traz para dentro da instituição a participação das famílias e do poder público em cujo teor serão atacados os pontos frágeis da unidade de ensino e no cuidado no tratamento com as pessoas, que os resultados aparecem.

A Constituição Federal comanda todo o ordenamento jurídico brasileiro, por força do princípio da primazia constitucional e também considerando toda a normatização que envolve o sistema educacional brasileiro, far-se-á neste texto uma reflexão sob o prisma constitucional para auxiliar na materialização da Educação como Direito Social exigível pelo cidadão e sendo um dever de Estado.

\section{O DIREITO À EDUCAÇÃO NA CF/88: BREVE ABORDAGEM}

A partir da promulgação da Constituição Federal/1988, no sistema jurídico brasileiro a Educação foi alçada ao patamar de Direito Fundamental em razão de sua relevância dentro da pretensão de se construir o bem comum para atingir o objetivo de se ter no país uma sociedade mais justa.

De início e para ressaltar essa relevância, tem-se no art. 24, VII da CF/88, que define os casos em que possa haver permissão de intervenção da União nos Estados e Distrito Federal, o que é uma exceção à ordem constituída, o artigo constitucional mencionado autoriza que a União intervenha num desses entes federativos, quando estes não cumprirem o mínimo da receita no investimento em Educação. 
No art. 35 caput e inc. III consta a disposição de os Estados intervirem nos municípios e a União em municípios localizados em Território Federal se houver o descumprimento quanto ao mínimo de receita destinada à educação. Neste caso, o art. 212 da CF/88, define como aplicação anual, nunca menos de $18 \%$ (dezoito por cento) para a União, e os Estados, Municípios e Distrito Federal, nunca menos de $25 \%$ (vinte e cinco por cento) da receita resultante de impostos.

Há que registrar-se que no campo da Educação com o advento da $\mathrm{CF} / 88$, foi assumido um compromisso do Estado com o ensino público, em especial no que diz respeito ao seu financiamento.

A Constituição Federal de 1988 estabeleceu que a educação é um direito social e definiu que os responsáveis pelo seu provimento são o Estado e a família. Para resguardar o direito à educação, o Estado estabeleceu a estrutura e as fontes de financiamento. Ao determinar a vinculação de recursos financeiros para a educação, a Constituição garantiu percentuais mínimos da receita resultante de impostos à manutenção e desenvolvimento do ensino: $18 \%$ da receita da União e $25 \%$ da receita dos estados, Distrito Federal e municípios, incluindo-se as transferências ocorridas entre esferas de governo e o salário educação. $\mathrm{O}$ conceito expresso na Constituição Federal assevera, portanto, que o financiamento adequado das políticas educacionais se traduz em alicerce para a construção do sistema nacional articulado de educação e, conseqüentemente, para o alcance das metas contidas em planos nacionais como o Plano Nacional de Educação (PNE). Contudo, para o acesso eqüitativo e universal à educação básica e a elevação substancial de alunos matriculados na educação superior pública, urge aumentar o montante estatal de recursos investidos na área, além de solucionar o desequilíbrio regional. (Documento-Referência - CONAE2010 - EIXO V - Financiamento da Educação e Controle Social) - (BRASIL, 2010)

Ao considerar que todo o ordenamento jurídico obedece a carta magna, por força do princípio da primazia constitucional e também ao analizar toda a normatização que envolve o sistema educacional brasileiro, far-se-á neste momento uma reflexão sob o prisma constitucional para auxiliar na materialização da Educação como Direito Social exigível pelo cidadão e um dever de Estado.

A classificação da Educação como Direito Social encontra-se insculpida no artigo $6^{\circ}$ da Constituição Federal/1988, in verbis: "art. $6^{\circ}$. São direitos sociais a educação, a saúde, o trabalho, a moradia, o lazer, a segurança, a previdência social, a proteção à maternidade e à infância, a assistência aos desamparados, na forma desta Constituição".

O legislador atribuiu importância à educação, que no art. $7^{\circ}, \mathrm{IV}$, da $\mathrm{CF} / 88$, ao explicar a finalidade do salário mínimo, consta entre as necessidades básicas do trabalhador a serem supridas por este, a Educação, ou seja, a educação consta como requisito mínimo a ser garantido pelo Estado brasileiro a todo e qualquer cidadão brasileiro.

Tavares, (2012, p. 837) entende direitos sociais como direitos "que exigem do Poder Público uma atuação positiva, uma forma atuante de Estado na implementação da igualdade social dos hipossuficientes. São, por esse exato motivo, conhecidos também como direitos a prestação, ou direitos prestacionais". Assim sendo, julga-se que Direitos Sociais sejam liberdades positivas e neste contexto, Silva (2009, p. 286-287), entende que os direitos sociais,

São prestações positivas proporcionadas pelo Estado direta ou indiretamente, enunciadas em normas constitucionais, que possibilitam melhores condições de vida aos mais fracos, direitos que tendem a realizar a igualização de situações sociais desiguais. São, portanto, direitos que se ligam ao direito de igualdade. (SILVA, 2009, P. 286-287) 
Pode-se propor que a Educação é um Direito Humano no sentido amplo da expressão. Num sentido mais restrito trata-se de um bem público e tanto em um caso como em outro deve ter a tutela do Estado, que tem a obrigação de patrocinar e garantir esse direito a todos os brasileiros.

Numa demonstração da preocupação com essa responsabilidade estatal, a Constituição Federal/1988 apresenta em seu capítulo III, Seção I, todo o subsistema constitucional da educação, que disciplina princípios e preceitos educacionais. Ao dispor no art. 205, que: "a educação, direito de todos e dever do Estado e da família, será promovida e incentivada com a colaboração da sociedade, visando ao pleno desenvolvimento da pessoa, seu preparo para o exercício da cidadania e sua qualificação para o trabalho".

Este artigo constitucional esclarece que a educação é um dever de Estado, mas coloca como corresponsável a família numa mesma graduação, porquanto diz ser "dever do Estado e da família", complementa com a indicação de que deve haver a colaboração da sociedade e implica dizer que, no que tange à Educação a família divide a responsabilidade com o Estado e que a sociedade deve participar para proporcionar o desenvolvimento da pessoa humana.

No art. 205, a palavra "educação" foi empregada no sentido de "educação escolarizada", isto é, como processo formal, regular ou escolar, vale reforçar. Três motivos justificam a opção do constituinte: $1^{\text {a }}$ ) oficializar a escola como a instituição principal do processo ensino-aprendizagem; $2^{\circ}$ ) o regime democrático requer maior preparo e capacitação profissional, insurgindo daí a importância dos serviços prestados pela escola; $3^{\circ}$ ) a educação informal é intangível, nem sempre alcançando os mesmos resultados do ensino regular. (BULOS, 2008, p. 1364)

A Educação não pode ser confundida como prestação de serviço e de acordo com Hartill (2006, p. 56) "educação é um direito universal e não um serviço. A educação que se busca é de qualidade, possibilita a inclusão, permite o pleno desenvolvimento da potencialidade de cada pessoa, constrói o respeito à diferença, promove a equidade e a paz". Nessa direção Bulos (2008, p. 1363) afirma ser a educação "o caminho para o homem evoluir. Por isso, é um direito público, subjetivo, e, em contrapartida, um dever do Estado e do grupo familiar".

Já o artigo 206 da CF/88 descreve aquilo que se almeja como modelo de ensino a ser aplicado, "in verbis": art. 206. O ensino será ministrado com base nos seguintes princípios:

I - Igualdade de condições para o acesso e permanência na escola;

II- Liberdade de aprender, ensinar, pesquisar e divulgar o pensamento, a arte e o saber;

III - pluralismo de ideias e de concepções pedagógicas e coexistência de instituições públicas e privadas de ensino;

IV - gratuidade do ensino público em estabelecimentos oficiais;

V - valorização dos profissionais da educação escolar, garantidos, na forma da

lei, planos de carreira, com ingresso exclusivamente por concurso público de provas e títulos, aos das redes públicas;

VI - gestão democrática do ensino público, na forma da lei;

VII - garantia de padrão de qualidade;

VIII - piso salarial profissional nacional para os profissionais da educação escolar pública, nos termos de lei federal.

Ensino à luz do art. 206 é método de transmissão de conhecimentos e de capacitação do indivíduo através da educação escolarizada (BULOS, 2008, p. 1365), já o conceito de educação envolve todas as influências que o indivíduo recebe em sua vida, em diferentes instituições e 
circunstâncias variadas. Nestes termos, todo ensino é educação, mas nem toda educação é ensino ou educação escolar (MOREIRA, 1998, p. 56).

Relativamente ao inciso I do artigo 206, tem-se a Jurisprudência (STJ, MS 7.407/DF2001/0022843-7) rel. Min. Francisco Peçanha Martins que dispõe:

O Estado brasileiro não impõe métodos nem obriga a que as pessoas matriculem seus filhos em escola pública. Disciplina, sim, a frequência, estabelece diretrizes e bases da educação consoante a Constituição e as leis vigentes aprovadas pelo povo através de seus representantes no Poder Legislativo (art. $1^{\circ} \S 1^{\circ}$ da CF/88). E de nenhum modo impede ou proíbe os pais de ajudarem na educação de seus filhos. Ao revés os ajuda de toda forma, seja mantendo estabelecimentos de ensino direta ou indiretamente com bolsas de estudo, seja promovendo o pagamento de bolsas aos pais, para incentivá-los a dirigir os filhos à escola pública ou privada [...] (STJ, MS 7.407/DF -2001/0022843-7) rel. Min. Francisco Peçanha Martins)

Os demais incisos do art. 206, pode-se dizer que sejam autoexplicativos. Outros artigos constitucionais que tratam sobre a educação: art. 22, XXIV, que trata sobre a competência privativa da União para legislar sobre diretrizes e bases da educação nacional; art. 23, V, o encargo dos entes federativos para viabilizarem o acesso à Educação e o art. 24, IX, o desígnio de se legislar concorrentemente sobre temas educacionais (BULOS, 2008, p. 1363).

Acrescenta-se ainda o art. 214 que estabelece, in verbis: Art. 214. A lei estabelecerá o plano nacional de educação, de duração plurianual, visando à articulação e ao desenvolvimento do ensino em seus diversos níveis e à integração das ações do Poder Público que conduzem à: I erradicação do analfabetismo; II - universalização do atendimento escolar; III - melhoria da qualidade do ensino; IV - Formação para o trabalho; V - promoção humanística, científica e tecnológica do País.

Bulos, (2008, p. 1381), faz a seguinte anotação a respeito deste artigo:

Desejamos, em data bem próxima, ver cumprido o desígnio constitucional, merecedor de aplausos do art. 214. Não precisa dizer que, até hoje, o analfabetismo persiste, o atendimento escolar não logrou universalização, a qualidade do ensino piorou, a deformação para o trabalho cresce e a promoção humanística, científica e tecnológica inocorreu no primeiro decênio da Constituição “cidadã”. (BULOS, 2008, p. 1381).

Além dos artigos citados nas linhas antecedentes, a $\mathrm{CF} / 88$ dispõe ainda sobre a autonomia didático-científica, administrativa e de gestão financeira e patrimonial das universidades no art. 207; a abertura de espaço para a iniciativa privada no art. 209; a fixação dos conteúdos mínimos para o ensino fundamental no art. 210; o destaque do ente federativo município como partícipe dos sistemas de ensino no art. 211; a aplicação dos recursos públicos a escolas comunitárias, confessionais, filantrópicas no art. 213; e a efetivação do dever de Estado com a educação constante do art. 208, que trata da obrigatoriedade e gratuidade do ensino fundamental, da universalização do ensino médio gratuito, do atendimento educacional especializado aos portadores de deficiência na rede regular de ensino, educação infantil, em creche e pré-escola às crianças até cinco anos de idade e do acesso aos níveis mais elevados do ensino, da pesquisa e da criação artística segundo a capacidade de cada um.

Assim, poderá-se que, a CF/88 exprime especial atenção à Educação, bem como ao sistema de ensino, a partir da assunção da Educação ao patamar de Direito Fundamental, tratando-a efetivamente, como Direito Humano e como Direito Social em razão de sua relevância dentro da pretensão do constituinte de se construir o bem comum. 
No art. 210 o preceito deve ser analisado e avaliado através da Lei de Diretrizes e Bases da Educação Nacional, que é tratado na sequência.

Como apontado por Fiorillo, Maccari e Martins (2015) a Lei de Diretrizes e Bases da Educação Nacional (LDB) teve sua promulgação oito anos após a Constituição, e, segundo Sathler (2008), ela lei foi criada com o objetivo de interromper as práticas e os modelos imprimidos pela ditadura militar.

A LDB pode ser considerada a Constituição da Educação, tamanha a sua importância e abrangência no que tange a formação do ser humano para a vida em sociedade e tem sua base no art. 210 da CF/88 que traz a seguinte redação: art. 210. "Serão fixados conteúdos mínimos para o ensino fundamental, de maneira a assegurar formação básica comum e respeito aos valores culturais e artísticos, nacionais e regionais".

Em seu art. $1^{\circ}$ a LDB aduz: "a educação abrange os processos formativos que se desenvolvem na vida familiar, na convivência humana, no trabalho, nas instituições de ensino e pesquisa, nos movimentos sociais e organizações da sociedade civil e nas manifestações culturais".

Nesse sentido logra

[...] Assim, num panorama de estreitamento na oferta de empregos e de alargamento do espaço dominado pela tecnologia, a formação para o trabalho passa do modelo da qualificação para o modelo da competência. Ou seja, não mais se afirma a preparação para determinadas profissões ou empregos, mas a formação do indivíduo flexível, criativo e dotado de recursos de empregabilidade, ou seja, de competências e habilidades para responder aos novos e incertos desafios, e se sentir responsável pelos resultados alcançados em sua luta por sobrevivência e realização pessoal. (SAMPAIO E GALLIAN, 2013, p. 180-181).

Os níveis escolares a partir da LDB passam a ter nova denominação, sendo que a educação infantil, o ensino fundamental (antigo $1^{\circ}$ grau) e o ensino médio (antigo $2^{\circ}$ grau) passam a ser Educação básica e a carga horária mínima anual é de 800 horas (200 dias letivos), tendo o Ensino Fundamental prioridade podendo qualquer um do povo ou entidade exigi-lo através de provocação ao Ministério Público (art. $4^{\circ}$ e $5^{\circ}$ ).

A LDB, no que tange ao currículo, em seu artigo 26 considera uma base nacional comum, mas que pode ser complementada por uma parte que entenda ser necessária em razão das peculiaridades e conforme as características regionais.

Desse modo, a partir da interpretação do artigo 26 houve abertura para uma flexibilização dos currículos, pois se admite a incorporação de disciplinas que considerem o contexto e a clientela.

Para explicitar prioridades, selecionar, estruturar e organizar o currículo é preciso conhecer bem todas as influências que se fazem presentes nesse processo- não só o que já foi comentado sobre as escolhas dos professores, as sugestões e as críticas dos meios de comunicação, as peculiaridades locais, as características e necessidades de aprendizagem dos alunos. Também importa considerar, com análise cuidadosa, as tradições escolares, as diferentes tendências do pensamento pedagógico que direciona o foco do processo de ensino e aprendizagem, e as diretrizes nacionais comuns a todas as escolas do país, para situar nesse contexto os limites de atuação da escola. (SAMPAIO E GALLIAN, 2013, p. 185). 
Relativamente à estrutura curricular, em uma pesquisa sobre escolas bem sucedidas, Libâneo, (2009) aponta que o currículo deve ter adequada seleção e organização dos conteúdos, valorização das aprendizagens acadêmicas e organização do tempo para as aprendizagens e o clima para o estudo. Também nos indica a necessidade de acompanhamento com os alunos com dificuldades de aprendizagem.

O currículo deve ser organizado de forma a expressar na aprendizagem dos alunos a cultura que envolve a instituição, mas também essa organização deve auxiliar diretamente na formação do indivíduo com uma nova visão de mundo, em sua transformação através do conhecimento.

O processo de elaboração do currículo principia de uma proposta pedagógica e envolve as relações sociais e culturais, bem como de cunho político, com a participação da sociedade civil e atuação de educadores.

Não se pode afirmar que o currículo nasce na escola, pois surge de decisões políticas em torno da educação. Assim, se por um lado elaborar o currículo na escola é explicitar intenções e um plano para realiza-las, por outro lado o currículo é a expressão das forças presentes na sociedade - que legitimam o saber a ser distribuído e apontam o que deve acontecer nas escolas. (SAMPAIO E GALLIAN, 2013, p. 178)

A educação básica, no que diz respeito à sua organização (art. 23), poderá ser em séries anuais ou em períodos semestrais. Também poderá ser em ciclos ou em alternância regular de períodos de estudos ou ainda em grupos não seriados, tendo como base a idade, a competência e critérios outros, desde que o interesse do processo de aprendizagem esteja indicando como necessário.

Os Parâmetros Curriculares Nacionais (PCN) são um guia curricular organizado por disciplinas e por ciclos. O Ensino fundamental é dividido em quatro ciclos, cada um composto por dois anos letivos. Em cada ciclo, propõe-se que o aluno cumpra atividades escolares reunidas em todo de disciplinas-língua portuguesa, matemática, ciências, história, Geografia, educação artística e educação física. Essas disciplinas são consideradas fundamentais para que os alunos possam adquirir o conhecimento relevante e socialmente necessário. Por outro lado, o documento aponta $\mathrm{o}$ fato de que há "questões urgentes que devem necessariamente ser tratadas, como a violência, a saúde, o uso de recursos naturais, os preconceitos, que não têm sido contempladas por essas áreas" (Brasil, 1997a, p.23). como fazer para abordá-las? Os PCN propõem que estas questões contextual temas transversais que atravessariam todas as áreas. São eles: ética, saúde, meio ambiente, orientação sexual e pluralidade cultural (UFRJ, 2003)

Conforme o Quadro 1, houve uma mudança na nomenclatura indicada pelo CNE para a Educação Infantil e o Ensino Fundamental

Quadro 1: Nomenclaturas indicadas pelo CNE para a Educação Infantil e o Ensino Fundamental: 


\begin{tabular}{|l|l|l|}
\hline Etapa de ensino & Faixa etária prevista & Duraçäo \\
\hline $\begin{array}{c}\text { Educaçāo Infantil } \\
\begin{array}{l}\text { Creche } \\
\text { Pré-Escola }\end{array}\end{array}$ & $\begin{array}{c}\text { até } 5 \text { anos de idade } \\
\text { até } 3 \text { anos de idade } \\
4 \text { e } 5 \text { anos de idade }\end{array}$ & \\
\hline $\begin{array}{l}\text { Ensino Fundamental } \\
\text { Anos Iniciais }\end{array}$ & $\begin{array}{l}\text { até } 14 \text { anos } \\
\text { de } 6 \text { a } 10 \text { anos } \\
\text { de } 11 \text { a } 14 \text { anos }\end{array}$ & $\begin{array}{c}9 \text { anos } \\
5 \text { anos } \\
4 \text { anos }\end{array}$ \\
\hline
\end{tabular}

(BRASIL, 2006, p.8)

Apresenta-se também o Quadro 2 com dados que ilustram os ciclos por meios dos quais os ensinos Fundamental e Médio estão organizados.

Quadro 2: Alterações na organização e implementação para a Educação Infantil e Ensino Fundamental

\begin{tabular}{|l|l|l|l|l|l|l|l|l|l|l|}
\hline \multicolumn{2}{|l|}{$\begin{array}{l}\text { RESOLUÇÃO } \\
\text { No } 3\end{array}$} \\
CNE/CEB
\end{tabular}

Fonte: BRASIL, 2006, p. 7.

Outro ponto a se destacar na LDB é a legitimação dada por ela ao que se denomina "progressão continuada" (art. 24; art. 32, inc. $2^{\circ}$ ), que consiste na aprovação automática de alunos da $1^{\mathrm{a}}$ a $5^{\mathrm{a}}$ série. Essa progressão, no entanto, embora se entenda automática contém o pressuposto de que deve haver um acompanhamento personalizado e tem por objetivo 
desestimular a evasão escolar, bem como a repetência, o que por sua vez desestimula a permanência dos alunos, em especial nos primeiros anos de estudo.

No art. 67 é assegurado ao profissional da educação: um piso salarial profissional, o aperfeiçoamento continuado, licenciamento periódico remunerado, condições adequadas de trabalho o que denota preocupação da busca pela valorização da atividade. Também anota que haja a progressão funcional baseada na titulação ou habilitação e na avaliação de desempenho. Relativamente à formação mínima para exercício do magistério na educação infantil, o art. 62 cria os institutos Superiores de Educação para ministrar cursos de licenciatura em nível superior.

Em razão deste trabalho estar voltado para a gestão escolar não se pode deixar de mencionar o art. 206 da CF/88 onde estão estabelecidos os princípios sobre os quais o ensino deve ser ministrado, em especial a denominada "gestão democrática" no ensino público.

Antes, porém, de se falar em gestão democrática, há que se abordar e buscar incorporar o tema principal que é a democratização da educação cujo conceito é mais abrangente do que simplesmente a criação de conselhos e a participação nas decisões.

Essas constatações contribuem para a compreensão de que a democratização do ensino não se dá somente pela garantia de acesso, requerendo sua oferta com qualidade social, para otimizar a permanência dos estudantes e, desse modo, contribuir para a melhoria dos processos formativos e a participação cidadã. (DOURADO, 2007, p. 940).

Democratizar, se entende também como sendo ampliar o atendimento escolar, participar ativamente de todo o processo, dar transparência aos processos, ter autonomia para fiscalizar, acompanhar e influenciar nas decisões.

A democratização é mais do que apenas o acesso e a ampliação do atendimento escolar, vez que mais do que facilitar o acesso há que se cuidar da permanência desse aluno no sistema e paralelamente a isso que ele tenha um ensino de qualidade.

A partir dessas premissas, ou para ter as condições básicas elencadas anteriormente o caminho da gestão escolar, passa obrigatoriamente pela ação do gestor que dará à escola o perfil que ele mesmo deseja.

\section{CONCLUSÃO}

Ao conscientizar-se que não se faz um país sem um investimento portentoso em educação. Verifica-se as dificuldades de se fazer educação em um país de dimensão continental feito o Brasil. Toda comunidade docente, associativa da educação e sindical da educação tem uma ideia do que se deve fazer para melhorar o sistema de ensino do país.

O que pouco se fala, é que uma barreira existente para que se dê início a uma mudança substanciosa, de cunho estrutural e com a profundidade necessária é que o universo que envolve intelectuais da educação, pensadores da educação, operadores da educação, enfim, está contaminado ideologicamente.

Afora isso há que se considerar o lado prático, o lado técnico da questão a começar com o planejamento, ou constata-se, a falta de planejamento.

A falta de planejamento governamental e na gestão escolar gera a busca por resultados por opinião deixando de lado os conceitos necessários à implantação de qualquer projeto. Quando não há, enfim, preocupação com o planejamento de longo prazo, vez que se busca o resultado imediato, ainda que este não confira aos interessados as condições ideais de efetividade, é como se aplicasse à consecução do projeto o sistema de tentativa e erro.

Ao gestor que não planeja vale mais, muitas vezes desfazer o que poderia dar certo ou que caminhava para dar certo do que fazer o que realmente dará resultado num prazo mais longo, 
apenas impulsionado pela ânsia do resultado imediato, ainda que sem consistência ao longo do tempo.

A falta de planejamento muitas vezes está vinculada ao pensamento tradicional, qual seja, a manutenção do status quo, que por sua vez dá mais segurança àqueles que comandam a máquina pública, vez que não inclui riscos, ainda que os resultados não sejam suficientes ou consistentes.

Assim como a inovação, contrariamente ao pensamento tradicional, exige uma boa dose de risco e de tempo para gerar resultados o que, politicamente no Brasil é incompatível em razão da falta de segurança que o agente público tem enquanto em seu cargo e da relevância que ele próprio se dá para deixar "sua marca" enquanto permanece no cargo.

Observa-se assim, uma cultura de realizar-se toda e qualquer política pública ou implantação de novos métodos sem qualquer planejamento, vez que é praticamente certa a descontinuidade governamental e, por conseguinte, a descontinuidade de planejamento de longo prazo em todos os campos de atividade pública do país.

A falta de planejamento gera a busca por resultados por opinião deixando de lado os conceitos necessários à implantação de qualquer projeto. Não há, enfim, preocupação com o planejamento de longo prazo, vez que se busca o resultado imediato, ainda que este não confira aos interessados as condições ideais de efetividade.

Determinadas ações governamentais, para não dizer a maioria delas, têm uma conceituação lógica, complexa, fundamentada, linguagem rebuscada, apresentação pomposa, mas quase sempre se apresenta desnecessária ou intempestiva, ineficiente ou descuidada e somente implantada para marcar uma posição de determinado grupo ou determinado administrador.

Por considerar que o caminho para o sucesso de uma instituição escolar passa, obrigatoriamente, pela gestão a que está submetida, recomenda-se aos operadores da Educação que se utilizem de um sistema que, sempre que bem entendido e corajosamente aplicado resultou em relativo sucesso: a utilização do método indutivo de administração, ou seja, as ações devem se dar do menor para o maior. De baixo para cima. Da base para a cúpula.

\section{PROPOSIÇÃO}

Método Indutivo de Administração: Ações devem se dar do menor para o maior. De baixo para cima. Da base para a cúpula. Para dar início a esse raciocínio toma-se como base o ensinamento Tavares (2009, p. 1076):

“os municípios representam uma excelente fórmula de descentralização administrativa do estado. Quanto mais descentralizado o exercício do poder do Estado, maiores as chances de participação política do cidadão e, por conseqüência, mais elevado o nível democrático que se pode alcançar". (TAVARES, 2009,p. 1076).

Assim, dentro de uma estrutura administrativa macro e de um país de dimensões gigantescas como é o Brasil, é imprescindível que se compreenda a importância dos municípios na efetivação das políticas públicas e da implantação de novos métodos de gestão escolar, de gestão da educação e da modificação do sistema de ensino, nessa ordem.

Para maior detalhamento dessa descentralização e dando lastro ao raciocínio do método indutivo, pode-se reportar à Encíclica Centesimus Annus, de João Paulo II e expresso inicialmente na Encíclica Quadragesimo Anno, de Pio XI, em 1931 nos seguintes termos:

79. Verdade é, e a história o demonstra abundantemente, que, devido à mudança de condições, só as grandes sociedades podem hoje levar a efeito o que antes podiam até mesmo as pequenas; permanece, contudo, imutável aquele solene princípio da filosofia 
social: assim como é injusto subtrair aos indivíduos o que eles podem efetuar com a própria iniciativa e capacidade, para o confiar à coletividade, do modo passar para uma sociedade maior e mais elevada o que sociedades menores e inferiores podiam conseguir, é uma injustiça, um grave dano e perturbação da boa ordem social. O fim natural da sociedade e da sua ação é subsidiar (coadjuvar) os seus membros, não destruí-los nem absorvê-los.

80. Deixe, pois, a autoridade pública ao cuidado de associações inferiores aqueles negócios de menor importância, que a absorveriam demasiadamente; poderá então desempenhar mais livre, enérgica e eficazmente o que só a ela compete, porque só ela o pode fazer: dirigir, vigiar, urgir e reprimir, conforme os casos e a necessidade requeiram. Persuadam-se todos os que governam: quanto mais perfeita ordem hierárquica reinar entre as várias agremiações, segundo este princípio da função supletiva [princípio da subsidiariedade dos poderes públicos], tanto maior influência e autoridade terão estes, tanto mais feliz e lisonjeiro será o estado da nação.

Não se trata então e somente, de transferir ao município a execução de ações para suprir as suas próprias necessidades, mas de as comunidades assim procederem a partir de suas dificuldades com o estímulo e coordenação do município em que está inserida. Entenda-se as comunidades, como sendo as escolas, as associações, incluso neste contexto também as famílias.

Esta é a noção de subsidiariedade que em tempos muito recentes tem sido tratado como princípio de organização social, para viabilizar o desenvolvimento da pessoa humana.

Para alguns estudiosos a subsidiariedade tem fundamento no art. $1^{\mathrm{o}}$, inc. III da Constituição Federal/1988 sendo que para outros encontra o seu fundamento na própria natureza humana à medida que, em não sendo dadas à pessoa as condições para que ela possa realizar por si as tarefas que julga imprescindíveis para sua valorização pessoal, estará sendo negada a ela a própria condição de crescimento humano.

Tal posicionamento está em consonância com o princípio da subsidiariedade dos poderes públicos, porquanto entende-se que as ações devem obedecer as reais necessidades dos setores que estejam carentes de soluções para seus problemas e com Azanha (1990), quando este defende que a escola pública deve ter um duplo propósito: o de mobilizar a sociedade do município no sentido de despertar a responsabilidade de cada um em relação à escola pública e pressionar os políticos e governos. Esse princípio também tem sido fundamentado com o critério da proporcionalidade, conforme afirmou Tavares (2009).

Há que registrar-se que no campo da Educação com o advento da CF/88, foi assumido um compromisso do Estado com o ensino público, em especial no que diz respeito ao seu financiamento.

A Constituição Federal de 1988 estabeleceu que a educação é um direito social e definiu que os responsáveis pelo seu provimento são o Estado e a família. Para resguardar o direito à educação, o Estado estabeleceu a estrutura e as fontes de financiamento. Ao determinar a vinculação de recursos financeiros para a educação, a Constituição garantiu percentuais mínimos da receita resultante de impostos à manutenção e desenvolvimento do ensino: $18 \%$ da receita da União e $25 \%$ da receita dos estados, Distrito Federal e municípios, incluindo-se as transferências ocorridas entre esferas de governo e o salário educação. $\mathrm{O}$ conceito expresso na Constituição Federal assevera, portanto, que o financiamento adequado das políticas educacionais se traduz em alicerce para a construção do sistema nacional articulado de educação e, conseqüentemente, para o alcance das metas contidas em planos nacionais como o Plano Nacional de Educação (PNE). Contudo, para o acesso eqüitativo e universal à educação básica e a elevação substancial de alunos matriculados na educação superior 
pública, urge aumentar o montante estatal de recursos investidos na área, além de solucionar o desequilíbrio regional. (BRASIL, 2010)

O principal problema que enfrentam os municípios é a falta de autonomia na prática, pois, salvo raríssimas exceções os prefeitos são dependentes, quase que totalmente, do governo do estado.

Há de se considerar que cada escola tem suas particularidades fato que contribui para que cada uma deve ter um tratamento específico para os seus problemas específicos e confiar sua administração aos seus gestores, que com habilidade irá provocar a transformação do ambiente interno e externo tornando-os positivos. Ou seja, considera-se que a gestão irá transformará o comportamento das equipes diretiva, docente e administrativa, fazendo delas equipes colaborativas, partícipes de cada processo e com interesse em resultados satisfatórios.

Ao revés, sempre que a escola obtivera resultados expressivos estes estão imputados ao bom desempenho da gestão e da participação de todos os atores envolvidos no processo.

A confirmação da gestão como agente transformador está latente em escolas que dividem o mesmo bairro, possuem o mesmo nível de clientela, estão inseridas no mesmo sistema, pertencem ao mesmo ente federativo, os professores têm o mesmo padrão salarial e os resultados são completamente diferentes.

Difícil acreditar que possam dar certo a implantação de planos homogêneos para grupos heterogêneos; que ocorram resultados expressivos para questões em que se tenta implantar a planificação homogênea, quando há um discurso de ações em prol da diversidade. Mais fácil, no entanto, acreditar que tanto um quanto o outro podem ser mais bem assimilados e administrados a partir de um universo próprio, bem mais concentrado, com um espaço bem mais restrito.

O gestor escolar deve conduzir o seu mundo próprio com todos os seus fatores internos e externos próprios para obtenção dos resultados crescentemente favoráveis.

Relativamente à estrutura curricular, em uma pesquisa sobre escolas bem sucedidas, Libâneo, (2009) aponta que o currículo deve ter adequada seleção e organização dos conteúdos, valorização das aprendizagens acadêmicas e organização do tempo para as aprendizagens e o clima para o estudo. Também nos indica a necessidade de acompanhamento com os alunos com dificuldades de aprendizagem.

O currículo deve ser organizado de forma a expressar na aprendizagem dos alunos a cultura que envolve a instituição, mas também essa organização deve auxiliar diretamente na formação do indivíduo com uma nova visão de mundo, em sua transformação através do conhecimento.

O processo de elaboração do currículo principia de uma proposta pedagógica e envolve as relações sociais e culturais, bem como de cunho político, com a participação da sociedade civil e atuação de educadores.

Não se pode afirmar que o currículo nasce na escola, pois surge de decisões políticas em torno da educação. Assim, se por um lado elaborar o currículo na escola é explicitar intenções e um plano para realiza-las, por outro lado o currículo é a expressão das forças presentes na sociedade - que legitimam o saber a ser distribuído e apontam o que deve acontecer nas escolas. (SAMPAIO E GALLIAN, 2013, p. 178)

A partir dessa noção de subsidiariedade deve-se passar a ver as ações para a promoção da educação de forma inversa, qual seja, a partir da escola, a partir do município.

Da escola para o município, do município para o estado membro, do estado membro para a União. Nesta ordem posta para que se considere de forma concreta, o princípio das ações na escola e em não sendo possível a esta realiza-las que as passe, então, para o município. 
Os esforços, no entanto devem ficar a cargo da escola, pois na ideia geral, a própria comunidade deve se mobilizar para abrir caminhos a ela, escola, de suas necessidades e dificuldades.

E aqui, novamente, entra a ação do gestor. A movimentação, inclusive política se as dificuldades assim o demandarem, deve ter a participação direta do gestor no intuito de trazer para sua unidade escolar a participação do município e da comunidade que o rodeia.

O município deve, por seu lado, subsidiar essa comunidade permitindo-lhe desenvolver ações na área de Educação que lhes sejam possíveis desenvolver. O papel do município em relação à comunidade escolar, então, é o de promover, coordenar, estimular e auxiliar.

O papel do gestor deve ser o de identificar carências, agregar pessoas e equipes, produzir um ambiente interno favorável, administrar corretamente os recursos e dialogar com a comunidade buscando a participação desta nos destinos de sua unidade escolar.

O gestor da escola e sua equipe devem deixar de lado as práticas da substituição das ações que lhe são próprias e entendê-las concretas, deixando para o município, o estado membro e a União as ações e programas abstratos.

E entre as escolas, que seja aplicada por observação da experiência de outras escolas, por inteligente que deva ser, a utilização das melhores práticas, não de forma uniforme, homogênea, padronizada, mas adaptada às reais necessidades daquela comunidade escolar, naquele município em específico, uma vez que se deve ao gestor escolar o compromisso de ter a escola que ele pretende ter sem a interferência política ou político partidária com interesses outros.

\section{REFERÊNCIAS BIBLIOGRÁFICAS}

AZANHA, José Mário Pires. Uma idéia sobre a municipalização do ensino. Palestra feita pelo autor em agosto de 1990 na Fundação do Desenvolvimento Administrativo (FUNDAP). Estud. av. vol. $5 \mathrm{n}^{\circ} .12$ São Paulo. 1991

BULOS, Uadi Lammêgo. Constituição Federal Anotada. $8^{\mathrm{a}}$ ed. rev. e atual. Até a Emenda Constitucional no 56/2007 - São Paulo: Saraiva, 2008.

BRASIL. Constituição Federal de 1988. Promulgada em 5 de outubro de 1988. Disponível em http://www.planalto.gov.br/ccivil_03/constituicao/constituicao.htm. Acesso em 26 mai. 2016.

BRASIL, Ministério da Educação. Documento de Referência. 2010. Disponível em: http://portal.mec.gov.br/arquivos/pdf/conae/documento_referencia.pdf). Acesso em 14 mai. 2016.

BRASIL. Ministério da Educação. Secretaria de Educação Básica. Ampliação do ensino fundamental para nove anos: $3^{\circ}$ relatório do programa / Secretaria de Educação Básica. Brasília: Ministério da Educação, 2006. Disponível em: https://www.google.com.br/url?sa=t\&rct=j\&q=\&esrc=s\&source=web\&cd=2\&ved=0ahUKEwjO 48rP_9zXAhWDFJAKHfCFCPgQFggvMAE\&url=http\%3A\%2F\%2Fportal.mec.gov.br\%2Fseb \%2Farquivos\%2Fpdf\%2Frelatorio_internet.pdf\&usg=AOvVaw27KQj7fD5iK6SxDCEWVJoG. Acesso em: 26 mai. 2016.

BRASIL. Presidência da República. Lei de diretrizes e Bases da Educação n. ${ }^{\circ}$ 12.796, de 04 de abril de 2013. Disponível em: http://www.planalto.gov.br/ccivil_03/ato20112014/2013/lei/112796.htm. Acesso em 26 mai. 2016. 
BRASIL. Superior Tribunal de Justiça. Mandado de Segurança n. 7.407/DF. Impetrante: Carlos Alberto Carvalho de Vilhena Coelho e Márcia Marques de Oliveira de Vilhena Coelho. Impetrado: Ministro de Estado da Educação. Relator: Ministro Francisco Peçanha Martins. Brasília, 24 de abril de 2002. Disponível em:

http://www.mp.go.gov.br/portalweb/hp/42/docs/ms-ensino_fundamental-7407_stj.pdf. Acesso em: 02 ago. 2011.

DOURADO, Luiz Fernandes. Políticas e gestão da educação básica no Brasil: limites e perspectivas Educ. Soc., Campinas, vol. 28, n. 100 - Especial, p. 921-946, out. 2007 Disponível em http://www.cedes.unicamp.br acesso em 02 jun. 2015.

FIORILLO, Aurelio; MACCARI, Emerson Antonio; MARTINS, Cibele Barsalini. A EAD no BRASIL e a importância de competências subjacentes para o reconhecimento de cursos de acordo com a percepção de coordenadores de curso. Administração: Ensino e Pesquisa: Rio De Janeiro v. 16 no 1 p. 141-178 jan fev mar 2015. Disponível em: https://raep.emnuvens.com.br/raep/article/view/211/171. Acesso em 26 mai. 2016.

HARTILL, Richard. O financiamento da educação na América Latina. In: CAMPANHA Nacional pelo Direito à Educação. A educação na América Latina: direito em risco. São Paulo: Cortez, 2006, p. 56.

LIBÂNEO, José Carlos. As práticas de organização e gestão da escola e a aprendizagem de professores e alunos. Presente! Revista de Educação, CEAP, Salvador BA, 2009, jan/abr 2009.

MOREIRA, R. A estrutura didática da educação básica. In: MENESES, João Gualberto de Carvalho et al. Estrutura e funcionamento da educação básica: leituras. São Paulo: Pioneira, 1998, p. 156.

SAMPAIO, M. M. F; GALLIAN, C. V. A. Currículo na escola: uma questão complexa. In: MARIN, A. J. (org.). Escolas, organizações e ensino. 1 ed. Araraquara, SP: Junqueira \& Marin, 2013.

SATHLER, L. Referenciais de qualidade para a Educação superior à distância: Desafios de uma caminhada regulatória.Colabor@ - A Revista Digital da CVA-RICESU, v. 5,

n. 17, p. 61-76, 2008.

SILVA, José Afonso da. Curso de Direito Constitucional Positivo. 32a ed. Rev. E atual. - São Paulo: Malheiros Editores, 2009, pp. 286-287.

TAVARES, André Ramos. Curso de Direito Constitucional. 10 $0^{\mathrm{a}}$ ed. Rev. E atual. - São Paulo: Saraiva, 2012, p. 837.

UFRJ. Programa de Apoio à Melhoria de Ensino Municipal. Curriculo e Conceitos Básicos: texto 4. Disponível em: http:www.race.nuca.ie.ufrj.br/ceae/m2/texto4.htm. Acesso em 08 ago. 2003. 